\title{
Pengaruh Faktor Pribadi Dan Psikologi Terhadap Keputusan Berlangganan TV Kabel Transvision Di Kelurahan Tongkaina
}

\author{
Sharas Devi Harun \\ Lucky F. Tamengkel \\ Aneke Y. Punuindoong \\ Program Studi Administrasi Bisnis, Jurusan Ilmu Administrasi \\ Fakultas Ilmu Sosial dan Politik, Universitas Sam Ratulangi \\ sharasharun23@gmail.com
}

\begin{abstract}
This study aims to determine: (1) the influence of personal factors on the decision to subscribe to Transvision cable TV, (2) the influence of psychological factors on the decision to subscribe to Transvision cable TV, and (3) the influence of personal factors and psychological factors on the decision to subscribe to Transvision cable TV. This study uses a quantitative approach by collecting data through literature and questionnaire methods. This study also uses saturated sampling techniques or sampling techniques if all populations are sampled. The sample in this study were 98 Transvision cable TV customers who included the Tongkaina urban community in Manado. Data collection techniques use questionnaires that have been tested for validity and reliability. The data analysis technique used to answer the hypothesis is multiple regression. The results of this study indicate that: (1) Personal factors have a positive effect on subscription decisions, as evidenced by the value of t count which is 2.363 with a significance value of 0.020 , smaller than 0.05 and the regression coefficient has a positive value of 0.143. (2) Psychological factors have a positive effect on subscription decisions, as evidenced by the value of $t$ count of 2.114 with a significance value of 0.037, smaller than 0.05 and the regression coefficient has a positive value of 0.145 , and (3) Personal factors and psychological factors have a positive effect on subscription decision, evidenced by the results of $F$ count of 5.236 with a significance of 0.007 . The $R$ square value or coefficient of 0.099 shows that the ability of the independent variable in explaining the variation of the dependent variable is $9.90 \%$, while the remaining $90.10 \%$ is explained by other variables outside the study.
\end{abstract}

Keywords: personal factors, psychological factors, subscription decisions, transvision cable-tv.

\section{Pendahuluan}

Mewarisi tradisi perusahaan terbaik, mengedepankan sikap kerja keras, kerja cerdas, komitmen, dan sikap berpacu memberikan kontribusi yang luar biasa untuk menghasilkan sebuah mahakarya yang indah. Namun, hal tersebut tidak sejalan dengan apa yang diharapkan oleh perusahaan. Konsumen dalam memilih TV kabel seringkali mepertimbangkan beberapa faktor yang dapat mereka jadikan sebagai bahan pertimbangan dalam menggunakan TV kabel, faktor-faktor ini muncul dikarenakan banyaknya TV kabel berlangganan yang bermunculan saat ini. Apalagi beberapa masalah yang di temukan 
peneliti diantaranya di tv kabel berlangganan transvision ini selalu mengalami komplain dari para pelanggananya yang sering mengalami gangguan siaran ketika musim hujan dan juga mengalami tagihan yang tidak sesuai dengan promo yang ditawarkan dari pihak Transvision.

Sehinggah penurunan jumlah pelanggan aktif terjadi hingga pada bulan April 2017, namun pihak Transvision sudah berusaha melakukan upaya-upaya agar dapat menggait pelanggan baru dengan meningkatkan kualitas produknya, kualitas pelayanannya serta mengeluarkan promo dan paket terbarunya dengan harga yang lebih murah yang dapat dinikmati kalangan menengah kebawah. Keberhasilan Transvision dalam memperbaiki kinerjanya dapat terlihat dengan kenaikan jumlah pelanggan selama beberapa bulan terakhir ini.

Transvision adalah salah satu yang popular di antara TV kabel yang ada diIndonesia. Transvision merupakan perusahaan swasta nasional yang bergerak dalam bidang jasa penyiaran TV berbayar dengan memiliki izin penyelenggara siaran berbasis kabel dan satelit. Untuk layanan berbasis kabel cakupan telah tersebar di beberapa kota di Indonesia seperti Jakarta, Bandung, Semarang, Surabaya, Denpasar dan beberapa kota besar lainnya. Untuk yang berbasis satelit atau DTH (direct to home) cakupan mencapai siaran seluruh wilayah Indonesia yang termasuk dalam jaringan satelit Telkom-1. Transvision merupakan TV kabel berlangganan yang sebelumnya dikenal sebagai Telkomvision.

\section{Pemasaran}

Pemasaran telah didefinisikan dalam berbagai cara yang berbeda-beda namun pada dasarnya mempunyai inti yang sama. Perbedaan itu disebabkan karena meninjau dari sisi yang berbeda. Ada yang menitik berartkan pada segi fungsi kelembagaan, segi barang, segi manajemen, dan ada juga yang menitik beratkan pada keseluruhan segi sebagai satu kesatuan sistim. Dalam karya tulis ini penulis mengutip dari beberapa pendapat ahli saja: menurut (Kotler,1997:8) pemasaran merupakan proses sosial dan manajerial dimana individu dan kelompok mendapatkan apa yang mereka butuhkan dan inginkan dengan menciptakan, menawarkan dan mempertukarkan produk yang bernilai dengan pihak lain.

\section{Perilaku Konsumen}

Menurut Kotler dan Keller (2014:173), Perilaku konsumen merupakan studi tentang bagaimana individu, kelompok, ataupun organisasi memilih, membeli, menggunakan dan melenyapkan barang, pelayanan, ide atau pengalaman untuk memuaskan kebutuhan dan keinginan mereka. 
Tujuan kegiatan pemasaran adalah mempengaruhi pembeli untuk bersedia membeli barang dan jasa perusahaan. Pada saat mereka membutuhkan hal ini sangat penting bagi manajer. Perusahaan yang menggunakan analisis konsumen akan lebih mudah mencapai tujuannya disamping memiliki keunggulan dalam mengetahui dan menciptakan kesempatan-kesempatan yang mungkin diperoleh dari kebutuhankebutuhan konsumen yang belum terpenuhi. Hal ini terjadi karena pada dasarnya analisis perilaku konsumen yang dilakukan pada perusahaan bertujuan untuk mengetahui bagaimana konsumen memberikan jawaban berbagai stimulasi pemasaran yang dapat dikendalikan oleh perusahaan.

\section{Faktor-faktor Yang Mempengaruhi} Perilaku Konsumen

Menurut Kotler dan Armstrong (2014:159-174) keputusan pembelian konsumen dipengaruhi oleh empat faktor, diantaranya sebagai berikut:

1) Faktor Budaya

Budaya, sub budaya, dan kelas sosial sangat penting bagi perilaku pembelian. Budaya merupakan penentu keinginan dan perilaku paling dasar.

2) Faktor Sosial

Perilaku seseorang konsumen dipengaruhi oleh faktor-faktor sosial seperti kelompok acuan, keluarga serta peran dan status.
3) Faktor Pribadi

Kepribadian adalah karakteristik psikologis yang berada dari setiap orang yang memandang responnya terhadap lingkungan yang relatif konsisten. Kepribadian dapat merupakan suatu variabel yang sangat berguna dalam menganalisa perilaku konsumen.

4) Faktor Psikologi

Faktor psikologis sangat mempengaruhi perilaku konsumen dalam menentukan pemilihan suatu produk yang ditawarkan oleh produsen selaku penghasil barang dan jasa.

\section{Perilaku Konsumen Pada Produksi Jasa}

Jasa merupakan pemberian suatu kinerja atau tindakan kasat mata dan satu pihak kepada pihak lain. Pengertian tersebut merupakan pengertian umum dari jasa. Pengertian luas dari jasa yaitu kegiatan yang dapat diidentifikasi, dengan sifat tidak dapat diraba, yang direncanakan sebagai pemenuhan kepuasan dari konsumen.

Dalam kegiatan sehari-hari jasa tidak terlepas dari manusia, sebagai contoh kita membutuhkan baju sebagai pakaian yang kita kenakan dala sehar-hari, untuk mendapatkan sebuah baju kita membutuhkan seorang penjual baju yang memberikan jasa pelayan maupun jasa dari seorang penjahit, dan banyak contoh lainnya dalam kehidupan kita. 


\section{Proses Pengambilan Keputusan dalam}

\section{Pembelian}

Keputusan seorang pembeli juga dipengaruhi oleh ciri-ciri kepribadiannya, termasuk usia, pekerjaan, keadaan ekonomi. Perilaku konsumen akan menentukan proses pengambilan keputusan dalam melakukan pembelian. Menurut Kotler (2009) ada beberapa tahap dalam mengambil suatu keputusan untuk melakukan pembelian, anatara lain: pengenalan masalah, pencarian informasi, evaluasi alternatif, dan keputusan membeli.

\section{Presepsi Konsumen}

Persepsi adalah proses bagaimana seorang individu memilih, mengorganisasi kan, dan menginterpretasikan masukanmasukan informasi untuk menciptakan gambaran dunia yang memiliki arti.

\section{Metode Penelitian}

Penelitian ini menggunakan penelitian kuantitatif. Yaitu penelitian yang menggunakan analisis statistik berbentuk angka-angka matematis yang bersifat penjelasan. Sedangkan pendekatan yang di gunakan adalah pendekatan Regresi Linear berganda untuk mengukur hubungan antar variabel. Regresi Linear Berganda adalah regresi yang melibatkan hubungan antara satu variabel tak bebas (Y) dihubungan dengan dua atau lebih variabel bebas.

\section{Teknis Analisa Data}

a. Uji Validitas. Menurut Sugiono (2003:267) validitas menunjukkan sejauh mana alat pengukur untuk mengukur apa yang hendak diukur. Hasil penelitian yang valid bila terdapat kesamaan antara data yangterkumpul dengan data yang sesungguhnya terjadi pada obyek yang diteliti.

b. Uji Reliabilitas. Reliabilitas adalah suatu nilai yang menunjukan konsistensi suatu alat ukur di dalam mengukur gejala yang sama. Setiap alat pengukuran seharusnya memiliki kemampuan untuk memberikan hasil pengukuran yang konsisten.

\section{Uji Asumsi Klasik}

a. Uji Normalitas. Menurut suliyanto (2005) dalam (Vicky Estri Utami. 2017), uji normalitas diperlukan untuk mengetahui residul yang diteliti berdistribusi normal atau tidak.

b. Uji multikolinieritas. Menurut Nugroho (2005) dalam (Vicky Estri Utami. 2017), uji multikolinieritas diperlukan untuk mengetahui ada atau tidaknya peubah independent yang memiliki kemiripan dengan peubah independent lainnya dalam satu model regresi.

c. Uji heterokedastisitas. Menurut Ghozali ( 2005 ) dalam (Vicky Estri Utami. 2017), uji asumsi ini 
heterokedastisitas bertujuan menguji apakah dalam model regresi terjadi ketidaksamaan varian dari residual satu pengamatan ke pengamatan lainnya.

\section{Analisis Regresi Linear Berganda}

Analisis regresi linier berganda di gunakan untuk mengetahui ada tidaknya pengaruh antara faktor pribadi, faktor psikologi terhadap keputusan berlangganan.

\section{Hasil Penelitian}

a. Uji Validitas

Diperoleh hasil yaitu, seluruh pernyataan kusioner baik itu pada variabel independen dan varibel dependen dinyatakan valid. Dapat dikatakan valid karena seluruh pernyataan variabel mengahsilkan tingakt koefisein lebih besar dangan tingkat signifikansi lebih kecil dari Alpha.

b. Uji Reliabilitas

\begin{tabular}{ccc}
\hline Nama variabel & koefisien alpha & keterangan \\
\hline $\mathrm{X} 1$ & 0,667 & Reliabel \\
\hline $\mathrm{X} 2$ & 0,605 & Reliabel \\
\hline $\mathrm{Y}$ & 0,637 & Reliabel \\
\hline
\end{tabular}

Berdasarkan hasil dari uji reliabilitas bahwa semua pernyataan pada kusioner dinilai reliabel karena nilai Cronbach's Alpha pada setiap variabel lebih besar dari 0,6 .

\section{Analisis Regresi Linear Berganda}

Berdasarkan hasil pengolahan data, output dari analisis regresi linear berganda diperoleh persamaan sebagai berikut

$$
\mathrm{Y}=6,284+0,143+0,145+\mathrm{e}
$$

1. Nilai Konstanta dari persamaan regresi linear berganda pada tabel diatas adalah 6,284 dan bertanda positif, hal ini menjelaskan bahwa jika Faktor Pribadi dan Faktor psikologis nilainya adalah 0 (Nol), maka Keputusan berlangganan adalah sebesar 6,284

2. Nilai koefisien Faktor Pribadi untuk variabel $\mathrm{X}_{1}$ sebesar 0,143 dan bertanda positif, ini menunjukkan bahwa faktor pribadi mempunyai hubungan yang searah dengan koefisien regresi. Hal ini mengandung arti bahwa setiap kenaikan Faktor Pribadi satu satuan maka variabel keputusan berlangganan (Y) akan meningkat sebesar 0,143 dengan asumsi bahwa variabel bebas yang lain dari model regresi adalah tetap.

3. Nilai koefisien Faktor Psikologi terstandarisasi untuk variabel $\mathrm{X}_{2}$ sebesar - 0,145 ini menunjukkan bahwa Faktor Psikologi mempunyai hubungan yang searah dengan koefisien regresi. Hal ini mengandung arti bahwa setiap kenaikan Faktor Psikologi satu satuan maka variabel keputusan berlangganan (Y) akan meningkat sebesar 0,145 dengan asumsi bahwa variabel bebas 
yang lain dari model regresi adalah tetap.

\section{Koefisien Determinasi $\left(\mathbf{R}^{2}\right)$}

Diperoleh nilai koefisien determinasi adjusted $R$ squere sebesar 0,099. Hal ini menunjukan bahwa pengaruh faktor pribadi, faktor psikologi terhadap keputusan berlangganan dapat diterangkan oleh model persamaan ini adalah sebesar 9,90\% sedagkan sisanya sebesar $90.10 \%$ di pengaruhi oleh faktor-faktor lain diluar penelitian.

\section{Uji Hipotesis:}

- Hipotesis pertama diajukan menyatakan bahwa di duga faktor pribadi berpengaruh positif terhadap keputusan berlangganan. Berdasarkan hasil penelitian, di peroleh nilai signifikansi $0,02<0,05$. Maka dapat disimpulkan bahwa H1 diterima, artinya variabel faktor pribadi memiliki pengaruh positif terhadap keputusan berlangganan.

- Hipotesis kedua yang di ajukan menyatakan bahwa diduga bahwa faktor psikologi berpengaruh terhadap keputusan berlangganan. Berdasarkan hasil penelitian, di peroleh nilai signifikansi $0,03<0,05$. Maka dapat disimpulkan bahwa H2 diterima, artinya variabel faktor psikologi memiliki pengaruh positif terhadap keputusan berlangganan.
- Hipotesis ketiga yang di ajukan menyatakan bahwa diduga bahwa faktor pribadi dan faktor psikologi secara bersamaan berpengaruh terhadap keputusan berlangganan. Berdasarkan hasil penelitian, di peroleh nilai signifikansi $0,007<0,05$. Maka dapat disimpulkan bahwa H3 diterima, artinya variabel faktor pribadi dan faktor psikologise cara bersamaan/simultan memiliki pengaruh positif terhadap keputusan berlangganan.

\section{Pembahasan}

Berdasarkan hasil penelitian diperoleh pengaruh yang signifikan diantara variabel-variabel bebas dan variabel terikat. Di mana untuk faktor pribadi Uji $\mathrm{T}$ menunjukan nilai $\mathrm{T}$ hitung untuk variabel Faktor Pribadi (X1) adalah sebesar 2,363 dengan tingkat signifikansi sebesar 0,020. T hitung yang bernilai 2,363 tersebut memiliki nilai yang lebih besar dibanding $\mathrm{t}$ tabel 1,98525. Sedangkan tingkat signifikansi memiliki nilai yang lebih kecil dari Alpha $(0,05)$, dari hasil tersebut menunjukan bahwa faktor pribadi memiliki pengaruh positif terhadap keputusan berlangganan. Untuk faktor psikologi Uji $\mathrm{T}$ menunjukan nilai $\mathrm{T}$ hitung untuk variabel Faktor Psikologi (X2) adalah sebesar 2,114 dengan tingkat signifikansi 0,037 . $\mathrm{T}$ hitung yang bernilai 2,114 tersebut memiliki nilai yang lebih 
besar dibanding $\mathrm{T}$ tabel 1,98525. Sedangkan tingkat signifikansi memiliki nilai yang lebih kecil dari Alpha $(0,05)$, ini menunjukan bahwa faktor psikologi memiliki pengaruh yang positif terhadap keputusan berlangganan. Dan untuk faktor pribadi dan faktor psikologi secara bersamaan/simultan menghasilkan nilai $\mathrm{F}$ hitung sebesar 5,236 dengan tingkat signifikansi 0,007. Karena tingkat signifikansi $<0,05(0,007<0,05)$ dan $\mathrm{F}$ hitung lebih besar dari F tabel (5,236> 3,09), ini menunjukan bahwa faktor pribadi dan psikologi secara bersamaan memiliki pengaruh yang positif terhadap keputusan berlangganan. Namun tingakat pengaruh kedua faktor ini terhadap keputusan berlangganan di katakan rendah, karena koefisien determinasinya hanya 0,099 atau 9,90\% variasi dari Keputusan Berlanggan dapat dijelaskan oleh model regresi ini, sedangkan sisanya sebesar $90.10 \%$ dijelaskan oleh variabel lain di luar penelitian.

\section{Kesimpulan}

Variabel Faktor Pribadi $\left(\mathrm{X}_{1}\right)$, berdasarkan hasil uji $\mathrm{T}$ yang terlihat pada tabel 11, yaitu T hitung yang memiliki nilai lebih besar dibandingkan $\mathrm{T}$ tabel. Sedangkan tingkat signifikansi memiliki nilai yang lebih kecil dari Alpha. Sehinggah dapat disimpulkan bahwa variabel faktor pribadi memiliki pengaruh yang signifikansi terhadap keputusan berlangganan. Dengan demikian hipotesis h1 di terima dan h0 ditolak karena adanya pengaruh yang signifikan dari faktor pribadi terhadap keputusan berlangganan.

Variabel Faktor Psikologi $\left(\mathrm{X}_{2}\right)$, berdasarkan hasil uji $\mathrm{T}$ yang terlihat pada tabel 11, yaitu $\mathrm{T}$ hitung yang memiliki nilai yang lebih besar dibandingkan $\mathrm{T}$ tabel. Sedangkan tingkat signifikansi memiliki nilai yang lebih kecil dari Alpha. Sehingga dapat disimpulkan bahwa variabel faktor psikologi memiliki pengaruh yang signifikansi terhadap keputusan berlangganan. Dengan demikian hipotesis h2 diterima dan h0 ditolak karena adanya pengaruh yang signifikan dari faktor psikologi terhadap keputusan berlanggan.

Variabel Faktor Pribadi dan Faktor Psikologi secara bersama-sama atau simultan berpengaruh signifikan terhadap keputusan berlangganan, dibuktikan berdasarkan hasil uji $\mathrm{F}$ didapatkan bahwa hasil nilai $F$ hitung lebih besar dari pada $F$ tabel, dan tingkat signifikansi lebih kecil dari Alpha. Hal ini menjelaskan bahwa dalam penelitian ini variabel Faktor Pribadi dan Faktor Psikologis secara bersamasama/simultan berpengaruh signifikan terhadap Keputusan Berlanggan. Dengan demikian hipotesis h3 diterima dan h0 ditolak.

\section{Saran}

Bagi TV Kabel Transvision, agar lebih memperhatikan faktor pribadi dan 
faktor psikologi dalam pengambilan

keputusan konsumen untuk meraih dan memperluas pasar sehinggah TV Kabel

Transvision bisa mengetahui apa yang diinginkan konsumen.

Bagi Peneliti Lain , agar bisa melanjutkan penelitian pada faktor budaya dan faktor sosial dimana kedua faktor ini dilihat memiliki pengaruh yang cukup luasa seperti yang dijelaskan dipembahasan.

\section{Daftar Pustaka}

Kotler, P dan Kevin,L.K.2009. Manajemen Pemasaran. edisi 13 Jakarta. Erlangga

Kotler, Philip dan Kevin Lane Keller. 2012. Marketing Management: Fourteenth Edition. New Jersey: Pearson Education, inc.

Kotler, Philip dan Gery Armstrong. 2014. Principles of Marketing: Fifetenth Edition. USA:Pearson Education, inc.

Kotler, Philip and Kevin Lane Keller, (2016): Marketing Management, 15th Edition New Jersey: Pearson Pretice Hall, Inc.

Pressindo.Bandung Analisis Perilaku Konsumen. Edisi pertama. Yogyakarta: BPFE.

Vicky Estri Utami. 2017. Analisis Pengaruh Faktor Personal dan Faktor Psikologi Terhadap Keputusan Pengguna Jasa Tv Satelit Indovision di Bandar Lampung. 